\title{
DIREITO E HOMINIZAÇÃO: DIREITO COMO A CONTEMPLAÇÃO DO OUTRO / LAW AND HOMINIZATION: LAW AS A RECOGNITION OF OTHERS
} Vinício Carrilho Martinez: Professor Adjunto II da Universidade Federal de Rondônia, junto ao
Departamento de Ciências Jurídicas. Doutor pela Universidade de São Paulo.

Fátima Ferreira P. dos Santos: Professora de Ética e Noções de Direito no Centro Universitário/UNIVEM/Marilia-SP. Mestre em Direito.

Também não tenho bens, muito menos dinheiro, Nem honra, nem glória no mundo

Goethe - Fausto Zero

Resumo: $\mathrm{O}$ artigo tem por finalidade relacionar a sociabilidade que é inerente ao direito, como processo de hominização e força civilizatória. É uma perspectiva em que o direito se apresenta com uma função social muito mais ampla do que o fluxo social/natural da coerção. O texto se constrói a partir de três possíveis narrativas que relacionam o Direito e o processo civilizatório, na construção psicossocial, moral e jurídica do Outro. Por isso, para efeito didático, está dividido em três partes: 1); Educação Inteligente; 2) Luta por reconhecimento; 3) Direito Social.

Palavras-chave: Direito Social, luta por reconhecimento, sociabilidade.

\begin{abstract}
The article aims to relate the law sociability as a hominization process and civilizatory power. That's a perspective in which law presents itself as a vaster social function than the social/natural coercion flow. The text was constructed from three possible narratives that relate law and the civilization process in the psychosocial, moral and legal construct of the other. That's why, for a better understanding, the article is divided in three parts: 1) Intelligent education; 2) Struggle for recognition; Social rights.
\end{abstract}

Key-words: Social Law, struggle for recognition, sociability

\section{Introducão:}

Sem reconhecer o Outro, a outra pessoa como equivalente a si mesmo, "o homem é estranho ao homem". Sem o Outro, o individualismo coloca a matéria, a propriedade como bem supremo. Como a mercadoria passa a ser o paradigma, a

vertente hegemônica, o homem se retrai a níveis de valoração inferiores.

Sem o Outro, o homem estranha a si mesmo. Sem o Outro, as outras pessoas que têm direitos e desejos, o homem não se reconhece, não se diferencia. Para ele, tudo não 
passa de uma mera pedra que pode ser quebrada, atirada, colecionada. É o estranhamento como negação social.

Sem o Outro, a mercadoria ocupa o lugar do homem e recebe todas as atenções. O humano, colocado como bem inferior, volta a níveis de bestialidade e de violência que julgávamos superadas. Sem que o homem seja um bem jurídico defendido, preservado a todo custo pelo Estado de Direito, nada parece frear a ânsia por ter, possuir e, para tanto, agir sem freios, receios para conseguir a propriedade da matéria.

O homem estranho a outro homem é a explicação mais realista para os crescentes níveis de indiferença ao social e de violência urbana. A chamada violência gratuita que se vê atualmente, com abuso de requintes de crueldade, é possível porque o violador não vê no seu objeto de conquista, uma outra pessoa.

É possível agir com tamanha barbárie porque o ato de tirar a dignidade, a vida, além das posses, é entendida pelo violador como equivalente a quebrar um copo, descascar uma laranja. Não há medo, receio da lei ou da coerção porque o violador julga que está agindo de forma correta. "Ora, se todos podem ter os bens que querem, sem compromisso, responsabilidade, a qualquer custo (a exemplo da maioria dos políticos e de muitos empresários) por que não eu?" - indaga-se o violador.

Diante do quadro crescente da mercadoria como valor-essência, o violador deixa de ser violador. Na verdade, o que o difere dos muitos corruptores da vida social (de colarinho branco) é que age com graus mais visíveis de violência. Os demais psicopatas - indiferentes a "dor dos outros", à sociedade, sem sentimento de remorso porque não se põe no lugar do Outro - cometem crimes sofisticados, encobertos pela burocracia, nuances da lei e pelo dinheiro já acumulado.

É óbvio que o impacto social desses criminosos, agindo pelo/sob Estado de Direito, é muito maior. O que os diferencia dos malgrados violadores comuns é que as mortes provocadas são escondidas pelo tempo e pelas estatísticas dos registros públicos. Afinal, como contabilizar quantas pessoas morreram/morrerão em decorrência dos recursos desviados da saúde?

Quantos não tiveram a socialização primária adequada, tornando-se violadores da posse das mercadorias, em razão do desvio de verbas da educação pública? É muito difícil quantificar esses males sociais. Mas não é difícil ver que a ausência do Outro como referência da formação humanista básica nos legou esse assustador momento de extrema antipatia social. 


\section{Quaestio Iuris}

vol.05, $\mathrm{n}^{\circ}$ 01. ISSN 1516-0351

É óbvio que aquele não interessado em ninguém, além de si mesmo, também não terá compromisso com a sociedade. Aliás, para esses violadores ricos e pobres, a sociedade é um conceito inatingível, indecifrável, irreconhecível. É similar a um materialista explicar o que é a metafísica; a uma religião sem dogmas; ao direito sem responsabilidade; à educação sem o Outro.

\section{$1^{\text {a }}$ Parte}

\section{Educacão Inteligente: Apreender com o Direito}

$\mathrm{Na}$ formação de uma comunidade superior, a exemplo do Estado - ou de muitas das comunidades submetidas e controladas pelo Estado -, a principal garantia é de que todos possam desenvolver a razão. Por isso, Estados bem organizados investem maciçamente em educação. Em decorrência, é correto afirmar que as sociedades equilibradas são eficientes ao promover e desenvolver o bom senso, o cumprimento das obrigações, o respeito à lei, o entendimento do direito como consecução da justiça em seus cidadãos.

Esta formação unificada pela razão induz nos sujeitos a capacidade de compreensão de que se pode/deve estabelecer ou alterar regras sociais (normas jurídicas) para a organização da vida social. Forma-se, portanto, a capacidade do pensamento abstrato forma de raciocínio em que se é eficiente para relacionar o particular e o geral, e depois retornar às particularidades. A educação inteligente estimula o pensamento abstrato.

Esta capacidade de relacionar e também de associar o particular e o geral é essencial à aplicação das normas e das regras. É exatamente este vai e vêm entre particular/geral que impede ou inibe o cometimento de crimes. O sujeito é portador do sentimento de se ver como parte ativa da vida social, mediante o estabelecimento das obrigações e isto se deve, efetivamente, à capacidade de elaboração do pensamento abstrato. O sujeito inteligente avalia o caso concreto, o particular, em confronto/comparação com a regra geral. A relação entre o particular e a regra geral recebe o codinome de subsunção - e que não é a fuga da realidade, muito pelo contrário, pois a realidade está contida na cultura (política) que se compara com a lei. Efetivamente, quando o próprio caso concreto é abstraído, elevando-se, livrando-se dos marcos de sua concretude para ser comparado, "medido pela lei", efetiva-se o pensamento abstrato que está expresso na subsunção. Assim, por efeito da subsunção, o sujeito consegue se comunicar com as instituições e com os demais seres sociais. A subsunção, como uma parte do pensamento 
abstrato, permite ao indivíduo a descentralização, "sair de si”, para se encontrar no Outro e no espaço coletivo representado pela lei e pelo direito.

No caso específico da subsunção, o Outro é identificado com a lei, pois a lei representa o interesse geral, coletivo e não deveria ser afrontada. Os (relativamente ou totalmente) incapazes de associar a si e a generalidade expressa pela lei são os que cometem os crimes, pois veem na lei algo abstrato, distante de si e sem sentido, como algo que não precisa ser cumprido. Para quem é incapaz de elaborar o pensamento abstrato, o geral não existe, à medida em que o concreto é o que conta, por estar presente diretamente na vida, na imediatividade de suas ações.

O que separa o adulto da criança, o capaz do incapaz, o sujeito do direito (a quem a lei não o atinge como "punição") e o objeto (a quem cabe alguma restrição de direitos), o socializável do egocêntrico, o embrutecido do inteligente (o sujeito capaz de pensar o concreto, abstrair, mas como "concreto-pensado"), o bom senso da alienação (potência ou capacidade retirada de si), é a educação que propicia e estimula o pensamento dirigido ao Outro. O que ainda leva a concluir que a consciência do direito e do dever, bem como a distinção entre o devido e o indevido, concatenar certo/errado, parte dessa mesma condição associativa entre o particular (o que me interessa pessoalmente, imediatamente) e o geral: o que também me interessa, mas apenas mediatamente, com a interposição do Outro. Afinal, o Outro é abstrato - Quem é esse Outro? Onde está? Por que nome responde? Ao mesmo tempo em que é próximo, concreto, porque é semelhante a mim em desejos e necessidades, é igual a mim em direitos e é equivalente a mim fisicamente, biologicamente.

Portanto, um Estado fortalecido é aquele que investe em educação: 1) comunicar-se pela língua; 2) abstrair pelo pensamento; 3) tomar decisões por si só. Somente desse modo é que se pode afirmar que "o Estado é a ordem estabelecida e dirigida a eles, a nós, aos outros, a todos". A comunicação formulada pela "razão livre" torna as regras legítimas, compreensivelmente aplicadas aos outros e a mim, pois se nem todos podem participar de sua elaboração, ao menos, todos poderiam compreender seu significado e alcance. A comunicação entre duas pessoas livres permite a formação do pensamento abstrato; mas, de modo inverso, se há somente uma via para a razão, "o pensamento é único", como se houvera um direito unilateral de se expressar, de se impor como regra particular ao geral, aos demais. 


\section{Quaestio Iuris}

vol.05, nº 01. ISSN 1516-0351

O pensamento único se confunde com a "generalização do particular", pois um se impõe aos demais. Suprimindo-se as diferenças entre o particular e o geral institui-se a ideologia, como desmerecimento do direito, como se fosse um tipo de "direito particular", um privilégio que se quer impor a todos. O "governo dos homens" é um governo com forma egoísta, com base na lei "lei privada" (privi legem) transmitida pela vontade de um único agente. Obviamente que o governo dos homens, quase sempre limitado como privilégio (lei privada), é um governo baseado em leis injustas; uma vez que se a lei não for expressão do geral, se exprimir somente o interesse privado, será uma lei injusta.

O "governo das leis", ao revés disso, dirige-se pela vontade geral expressa na lei, no direito; o governo das leis é muito mais inteligente porque se baseia no pensamento abstrato. Somente desse modo se pode dizer que "a Razão Pública se expressa pelos atos do Estado", quando a norma jurídica se aplica ao indivíduo (particular) e ao Estado (como o contexto geral). Por isso, sem a educação que nos ensine a compreender o que se lê e seu alcance futuro (pensamento abstrato), continuaremos a dizer que "a lei não pega". A lei não pega porque não a "apreendemos"; não tomamos para nós, cada um a seu modo, para si, o que deve ser de comum alcance e interesse. A lei não pega porque não consideramos válido para os outros, aquilo que tomamos para nós como significativo, relevante, impositivo.

As associações que estabelecemos entre nós e o direito se fortalecem com esta mesma capacidade elaborada pelo pensamento abstrato, em que somos capazes de "apreender o geral" - trazer para si - como algo a ser vivificado, verificado concretamente em nossa vida; assim, o direito, a lei, a norma jurídica se tornam concretos em nossas vidas, não apenas nos rodeiam, mas habituam-nos, estando próximos, inseridos. Também apreendemos o geral quando internalizamos o direito, a lei, como o que faz sentido seguir, como algo correto e que é validável. Daí que internalizar a lei é apreender o geral que ela guarda e expressa; fala-se de uma “aculturação acrítica" porque não é correto, coerente e lógico, criticar o Outro que se apresenta e é representado na forma do direito. Até porque o Outro que se tem na lei é espelho de nossas intenções. É como se dissesse que "cada povo tem o governo (e, sobretudo, a lei) que merece". A norma jurídica, o direito, a lei são o geral em potência e daí vem sua força, obrigação (de fazer ou deixar de fazer), coerção, imposição para ser

Revista Quaestio Iuris, vol.05, nº1. ISSN 1516-0351 p. 144-157 148 
seguida por quem não é capaz de sozinho elaborar o pensamento abstrato. Em síntese, "apreender o direito" é efetivar, "concretizar como realidade", o pensamento abstrato.

Neste sentido, está correto dizer que o direito, a lei, a norma jurídica obrigam o infrator, quem está em desacordo com o geral da lei, a um processo de humanização. Obrigar à lei seria equivalente a obrigar o indivíduo ao pensamento abstrato, lógico e coerente com a sociedade. O direito é parte e infusor da humanização porque nos leva ou obriga a elaborar, desenvolver o que temos de melhor: o raciocínio lógico e o pensamento abstrato. Pois, o direito transforma, eleva a própria potência do raciocínio ao degrau elaborado, superior do pensamento abstrato que se aplica ao real: o concretopensado. O pensamento abstrato efetiva, desse modo, o direito em ato, e, ao efetivá-lo, legitima-o. É por isso que o direito representa o processo civilizatório, porque nos obriga a pensar como humanos, projetando-nos para fora - para além de si -, em direção ao Outro. O direito nos torna mais humanos porque nos obriga a pensar e a ver a sociedade que está além de nossos olhos. O direito é democrático porque estimula essa descentralização.

Como visto, o direito, a lei só são possíveis graças à formulação do pensamento abstrato, sob o qual nos vemos capazes de distinguir e de nos movimentarmos, no plano da consciência e da ação, entre o particular e o geral, o público e o privado, entre o concreto e o abstrato (e o concreto-pensado), e vice-versa. Esta capacidade de se projetar para lá, pondo-se no lugar do Outro, saindo daqui, dos domínios dos próprios interesses, é o que permite reconhecer o certo e o errado. O pensamento abstrato permite que não se viva erroneamente, ou seja, sob os designíos do pensamento mágico, da ideologia, da ideação, da alienação - entendida como negação, restrição, suspensão ou "perda do direito".

\section{$2^{\mathrm{a}}$ Parte}

\section{Luta por reconhecimento: O Direito ao alcance da Humanidade}

Como diz Honneth (2003), se não há o Outro, é porque não há o EU ou porque só há o eu-mesmo-e-nada-mais. A Luta por Conservação da Razão de Estado, não raramente, vê-se repleta de obstáculos, estranhamentos, negações ou ofendículos para que não se converta ou se metamorfoseie em Luta pelo Reconhecimento. Normalmente, 


\section{Quaestio Iuris}

a Luta por Conservação é empregada no contexto do individualismo metodológico para sugerir que indivíduos isolados lutem pela sua autoconservação de forma utilitarista.

Por seu turno, o reconhecimento traz identificação (de si), atestação (social), responsabilidade (moral e jurídica) e efeito conciliador (do conflito à conciliação). Portanto, neste fluxo, pode-se observar a identidade $\left(\right.$ idem $=$ latim $^{1}$ ) como constância, diferenciação (do passado do agente político e do sujeito de direitos) e reconstrução (de si, da cultura).

O reconhecimento da identidade, obviamente, assegura o entendimento de que se trata de um semelhante e não de o "mesmo". Aliás, do contrário, estaria correta a afirmação de Baudrillard de que: "Onde havia o Outro, adveio o mesmo" (1990). Sem o Outro, só há um campo fértil para o Eu-mesmo. É lógico que nada fere mais o reconhecimento do que a mesmice, quando não se tem nenhuma possibilidade de descentramento, de alteridade. O sentido apregoado a idem, portanto, não poderia ser diferente: trata-se de reconhecer o diferente como o semelhante - nunca será o mesmo, visto que é diferente. No entanto, o Outro pode ser tratado igualmente, aos já reconhecidos como iguais, seja pela legalidade, seja pela reciprocidade.

Idem tem o tônus da igualdade, da veracidade atestada pela analogia (ou seja, deve suplantar a verossimilhança ${ }^{2}$ ), deve ser perfeitamente passível de reconhecimento como igual. É semelhante em substância e deve ser equiparado ao "mesmoreconhecido". Suas particularidades serão reconhecidas e resguardadas em razão da veracidade atestada pela analogia.

Idem será o mesmo sob uma única circunstância: "com o mesmo significado, o mesmo tratamento". Id est, "isto é, ou seja", quando a semelhança aproximar e equiparar as diferenças. Portanto, se, somente se, ibidem ("no mesmo lugar") ou topos (na mesma topologia política) em que se configuram os estatutos de reconhecimento dos mesmos sujeitos e direitos, daqueles que se tornaram semelhantes por razões apriorísticas de cultura, imposição de direito, origem social, atribuição de status. Desse modo, a fortiori, “com mais forte razão", a inclusão da diferença, equilibrada pela analogia com o já-reconhecido, implicará no reconhecimento do Outro, a partir de categorias elencadas como possivelmente conflitantes, mas não excludentes.

\footnotetext{
${ }^{1}$ Idem será "da mesma maneira" tratado como o Outro, em que "este-Outro" pode transmitir suas opiniões, de acordo com a mesma categorização.

${ }^{2}$ Como mera probabilidade.
} 
O reconhecimento atribuirá ao Outro a potência (jurídica, política, cultural) de se equiparar ao que já foi admitido. O diferente será virtualmente (por força da abstração jurídica ou reconhecimento cultural) admitido, inserido nas mesmas condições, receberá uma equiparação virtual:

A palavra virtual vem do latim medieval, virtualis, derivado por sua vez de virtus, força, potência. Na filosofia escolástica, é virtual o que existe em potência e não em ato. $\mathrm{O}$ virtual tende a atualizar-se, sem ter passado no entanto à concretização efetiva ou formal. A árvore está virtualmente presente na semente. Em termos rigorosamente filosóficos, o virtual não se opõe ao real mas ao atual: virtualidade e atualidade são apenas duas maneiras de ser diferentes (Lévy, 1996, p. 15).

O Outro, como idem, será virtualmente inserido até que o reconhecimento se complete, efetive-se, realize-se, como a semente que se torna árvore. Este reconhecimento, como florescimento, necessita da efetivação prática - como um conceito que se torna ação. Até que se realize, consubstanciando-se, o reconhecimento como inclusão é um projeto:

Etimologicamente, a palavra projeto deriva do latim projectus, particípio passado de projícere, algo como um jato lançado para a frente; relacionandose diretamente com outras palavras igualmente fecundas, como sujeito, derivada de subjectus/subjícere (lançado de dentro, de baixo), ou objeto, de objectum/objicere (lançado diante, exposto), ou ainda, trajeto, de trajectus/trajectare (passagem através de) (Machado, 1997, p. 64).

E todo projeto necessita de meios, ações, para que o conceito contido nos objetivos seja viável e não apenas uma possibilidade. O projeto de reconhecimento do sujeito e do direito precisa ser mais do que plausível. O Outro, como outro povo, precisa de equiparação para se engajar no espaço público, para não ser o mesmo-massificado: “O povo tornou-se público [...] Em momento algum as massas são engajadas de modo consciente política ou historicamente" (Baudrillard, 1993, p. 34).

Sendo assim, para o povo, diante do discurso competente do sujeito autocrático, o Poder e as formalidades do Estado de Direito não passam de mera paródia desse mesmo Poder. Para o povo, portanto, como o Poder Público está esvaziado de potência, o próprio simbolismo e a ritualística se revelam igualmente vazios, isto é, um outro fator que vem confirmar a paródia ou arremedo em que se transformaram as instituições. Diferentemente disso, na incapacidade de se abordar honestamente e de superar o "argumento contrário", o discurso competente do tecnocrata (Chauí, 1990) e do tecnofascista voltam-se à desqualificação pessoal do Outro-sujeito, agora como adversário. $\mathrm{O}$ 
Outro visto como aquém-do-diferente, como estrangeiro, exótico, díspare, requisita um esforço global de tolerância:

\begin{abstract}
Nem todos os nascidos no país, naturalmente, reagem desse modo [...] Mas o fato é que a presença, em um território, de muitos estrangeiros que começam a tomar a palavra desperta em cada um algum movimento de medo, de modo que ninguém está a salvo do ódio de si e do ódio do outro [...] $\mathrm{O}$ estrangeiro incomoda [...] Pois um estrangeiro é sempre um "exotista" é aquele que interroga, com sua própria existência, as normas, os usos e costumes da sociedade que o "acolhe ${ }^{3,}[\ldots]$ Não há homem (e grupo) totalmente aberto. Cada um precisa de seu próprio muro, sob pena de tornarse uma esponja e perder sua consistência [...] em uma sociedade tão conflituosa o termo sociedade pode se aplicar à realidade atual [...] Assim, é preciso manter a vigilância e não se fazer de santo, sob pena de, quem sabe, despertar a fera que cada um traz dentro de si (Enriquez, 2004, p. 57 - grifos nossos).
\end{abstract}

Sem o Outro, não há o "eu" e dessa junção entre "eu-Outro" é que nasce o direito, a nacionalidade, a "união do povo", mas isto quando em "nós" e não, exatamente, no "eu mais ele". A exigência do Outro implica em nossa sobrevivência, ultrapassando os limites do niilismo, egoísmo, narcisismo:

A sociedade pós-tradicional é um ponto final; mas é também um início, um universo social de ação e experiência verdadeiramente novo [...] uma sociedade global [...] No domínio da vida interpessoal, estar aberto para o outro é a condição da solidariedade social; em uma escala mais ampla, a oferta da "mão da amizade" em uma ordem cosmopolita global está eticamente implícita na nova agenda esboçada [...] Rompendo as aporias do pós-modernismo, podemos enxergar possibilidades de "democracia dialógica..." (Giddens, 1997, p, 130).

O Outro necessita de isonomia e de isegoria. Os gregos restringiam a cidadania aos que consideravam como indignos de abitar o espaço público, definindo-os como aneu logou ou idiotes, ou seja, aquele que não reúne capacidade e condições de pensar e de falar por si mesmo. Sem autonomia, não se dispõe dos princípios da isonomia ou da isegoria (liberdade de livre-expressão ${ }^{4}$ ) e, por isso, não colabora com a cidadania. Aqueles que, no mundo moderno, aceitem a condição de ser cliente (cliens = vassalo) não estão imunes a essas implicações. O Outro está à espera, atrás da janela e de onde nossos sentidos podem vê-lo, mas é preciso querer olhar.

\title{
$3^{\text {a }}$ Parte
}

\section{Direito Social: Não há Direito sem o Outro integral}

\footnotetext{
${ }^{3} \mathrm{O}$ intenso processo de guetualização patrocinado pelo Estado de Exceção nazista confere com este desejo de se livrar do Outro - aquele que incomoda pela mera existência.

${ }^{4}$ Do que também decorre o "direito de livre escolha".
} 
O barbarismo social, a nulidade do reconhecimento do direito, a comiseração moral que se abateu sobre a sociedade inclusiva lembram algumas situações. A principal delas é que o Direito não se efetiva sem a contemplação do Outro, como parte da formação humanista de quem ama as pessoas e não seus bens, status ou poder. É um pensamento utópico, mas é real, sensível à vida social, honesto com o espaço público republicano. $\mathrm{Na}$ verdade, não se trata propriamente de utopia, mas sim de virtualidade, ou seja, a realidade em sua outra face, pronta a se revelar (Lévy, 1996).

Desse modo, diante do "terror lancinante" que nos recorta, recheia e, receosos, nos enredamos com as coisas temerosas, quando não tenebrosas. Muitas são elas, mas só para citar: violência, pobreza, solidão, terrorismo, cataclismo do planeta (se bem que este último, poucos se dão ao luxo do interesse), a perda do direito. Pode-se dizer com certa margem de segurança que a vida em sociedade é um produto global e social. Há, assim, um ethos e um pathos a serem analisados na base e na origem da vida social. Como ethos implica em amor à humanidade (Humanismo) e paz: a sociabilidade requer reconhecimento do Outro, das outras pessoas. A sociabilidade é uma fabricação e requer sua depuração, não é algo natural. O ethos é a condicionante do direito social, é a garantia dessa sociabilidade; o ethos é a ética que pacifica o direito. Como pathos, doença mesmo, diz-se que a violência é um ato da razão praticada pelo Estado e seus corruptos, grupos econômicos dominantes, ou atende aos interesses dos simples ladrões e assassinos.

Contra a violência, que é a negação da vida social, Amos Óz, escritor israelense e Nobel da Paz, fala de um "amor lancinante", mesmo que seja um "amor nos tempos da cólera" ou em "tempos sombrios". As metáforas de Amos Óz são sobre as janelas da vida social que se abrem nos romances para todos que aceitam aprender sobre a vida dos outros. O que mais emociona, como empatia social, sociabilidade construída no reconhecimento do Outro, é a amplitude moral, humana que o romancista nos proporciona.

Em um caso determinado, o romancista faz um paralelo entre uma visitação turística e a leitura de um bom romance: "A leitura de um romance estrangeiro é um convite para visitar as casas de outras pessoas e lugares secretos de outros países" (Amos Óz, 04/11/2007). Depois diz que se você já não é apenas um turista, então, é capaz de parar numa rua e ver uma mulher na janela de sua casa (você é capaz de “reparar”, de "dar atenção"): "Mas, se é um leitor, você não apenas verá a mulher que 


\section{Quaestio Iuris}

olha da janela, mas estará com ela, na sala dela, na sua cabeça" (idem - grifos nossos). O leitor é esta pessoa aberta ao encontro do Outro, capaz da sociabilidade. Como voyeur, aquele que olha o infinito das relações sociais, o leitor está desapegado à pressa de consumir os dias e as noites na produção material. Só assim o romancista da vida honesta percebe a exterioridade não-compulsiva, obrigatória, determinante, mas amena, contemplativa, desembaraçada em relação às determinações externas que provém, por exemplo, da superestrutura, das obrigações e das penas, e da coerção da lei social.

Enquanto leitor da vida do Outro, em ação não-invasiva, mas compartilhada dos melhores sonhos e grupo de valores humanos, Amos Óz é sintético, objetivo: recomenda amar à Humanidade. $\mathrm{O}$ amor além de si mesmo é contemplação, a dor da espera, a esperança que é uma quase-angústia e um desejo incontrolável de ver o Outro. Esse é o amor das mulheres, principalmente se for mãe. É um amor que se dá na cabeça, nos olhos e no coração. É um amor de mulher que não tem medo e nem vergonha. Seguindose esta metáfora do "amor da mulher", para Amos Óz, o mundo precisa abrir suas janelas, arejar, oxigenar as estruturas arcaicas (na mente, no coração e na política). Precisamos de mais disposição para ver o Outro - porque isto equivale a olhar para cada um. Mesmo que o antagonismo esteja à flor da pele, precisamos ler o outro:

Leiam romances, caros amigos. Eles lhes dirão muito. E essas mulheres
também devem ler uma sobre a outra. Para saber, enfim, o que deixa a outra
mulher na janela aterrorizada, irada ou cheia de esperanças [...] todas as
mulheres, em todas as janelas, estão, no final do dia, precisando
urgentemente
http://www.estadao.com.br/suplementos/not_sup74999,0.htm). (Amos Óz,
idem).

Esta ida até a outra cabeça, ao seu interior, esse desprendimento do "euensimesmado", é o que traz a abertura para o Outro, para o "eu-ampliado". A literatura, a educação atenta ao direito do Outro, são pontes entre as pessoas. Seu reconhecimento nada mais é do que a construção de "pontes morais, sociais, intersubjetivas" entre os seres sociais: "Creio que a curiosidade possa ter uma dimensão moral. Creio que a capacidade de imaginar o outro possa ser um antídoto contra o fanatismo [...] De imaginar, realmente, os amores, os medos terríveis, a raiva, a paixão do outro" (idem, ibidem). Nossa Modernidade Tardia tem pouquíssima curiosidade (pelos outros) e, por isso, sobra hostilidade (ao Outro). Mas é factível, verdadeiro o sentimento que procura no direito o restabelecimento da "arte da aproximação entre atores em conflito de interesses". Por meio da liberdade de dialogar, é-nos permitido 
entender porque o aneu logou, o não-cidadão grego, estava excluído da vida: quem não fala, não vive.

O humanismo representado pelo direito do/ao Outro requer a construção de pontes-amigáveis entre os indivíduos - se o direito é, por origem, social, logo, pode-se concluir que só se realiza na relação social. Um direito restritivo, sem o Outro, desconsiderando-se o "amor das mulheres" é uma lei privada, sem esforço, sem repercussão, reconhecimento ou estofo social. Portanto, o construtor de pontes é um arquiteto da vida, pois seja literalmente, seja metaforicamente, sem pontes não há fluxo, e sem movimento não há vida. A vida é tudo, menos inerte e os bloqueios de seu livre movimento são, pode-se dizer, a antivida, a antipolítica e o antidireito. Por isso, os gregos clássicos também viam no político um arquiteto capaz de fazer dois mundos antagônicos, contrários, falarem entre si. Para Amos Óz precisamos de mais disposição para ver o Outro, captar seus sinais, localizar pontos de conexão (e mesmo que o antagonismo esteja à flor da pele).

\section{$\underline{\text { Uma última ponderação }}$}

Em suma, a educação inteligente estimula a solidariedade e a confiança, e esta é base do destino comum, em que cada um trabalha por si e pelos outros. Ao contrário do "destino manifesto", a crença de que nascemos predestinados a dominar os outros, a vida saudável é determinada pela simpatia e antipatia que uma sociedade é geradora.

O direito nos conecta em rede e esta rede tem seu Windows, assim como a vida social tem as janelas da alma (e a educação, a literatura são portas abertas para vermos e adentrarmos aos significados mais recolhidos). A literatura, mais do que metáforas, diminui as hostilidades com o aumento progressivo, interior (não-introspectivo) da curiosidade pelas circunstâncias independentes mas comuns a todos os leitores. Esse tipo de literatura (ou esse "modo de ler") não é, portanto, instrumental, enviesado, limitado ao uso/consumo imediato.

Vistas por esse prisma, a literatura e a educação inteligentes são infinitas aberturas ao reconhecimento. Mas, para ler o Outro, precisamos de muito mais janelas abertas. Parafraseando mais uma vez Amos Óz, grande parte da tragédia humana (especialmente na Modernidade Tardia) vem da incapacidade da maioria de nós, realmente de quase todos, de nos imaginarmos com o Outro. Amos Óz tem em mente as lindas imagens da Cabala Judaica, quando diz ao homem mau que "Deus conta as 
lágrimas das mulheres”, porque elas são sensíveis e porque choram a dor do mundo. Cada lágrima de mulher contém um sofrimento que recolheu da dor dos outros. E, por isso, o Outro é ser você, sem deixar de ser Eu.

\section{Referências}

AMOS Óz. Quem é a mulher na janela? Jornal O Estado de S. Paulo. Caderno Aliás, p. 04, 11 nov. 2007.

BARRETO, Vicente de Paulo (org.). Dicionário de Filosofia do Direito. São Leopoldo-RS :

Editora Unisinos : Editora Renovar, 2006.

BAUDRILLARD, Jean. À sombra das maiorias silenciosas: o fim do social e o surgimento das massas. São Paulo : Brasiliense, 1993.

A transparência do Mal: ensaio sobre os fenômenos extremos. Campinas-SP : Papirus, 1990.

CHAUÍ, M. Cultura e democracia: o discurso competente e outras falas. São Paulo : Cortez, 1990.

ENRIQUEZ, Eugene. O outro, semelhante ou inimigo? IN : NOVAES, Adauto de (org.).

Civilização e Barbárie. São Paulo : Companhia das Letras, 2004.

GIDDENS, Anthony. A constituição da sociedade. São Paulo : Martins Fontes, 1989. As consequências da modernidade. São Paulo : Editora da Universidade Estadual Paulista, 1991.

A vida em uma sociedade pós-tradicional. IN : Modernização Reflexiva. São Paulo: Editora UNESP, 1997.

Política, Sociologia e Teoria Social. São Paulo : Editora Unesp, 1998.

HONNETH, Axel. Luta por reconhecimento: a gramática moral dos conflitos sociais. São Paulo : Ed. 34, 2003.

LALANDE, André. Vocabulário Técnico e Crítico da Filosofia. $3^{\mathrm{a}}$ ed. São Paulo : Martins Fontes, 1999.

Revista Quaestio Iuris, vol.05, no 01 . ISSN 1516-0351 p. 144-157 156 
LÉVY, P. O que é o virtual? São Paulo : Editora 34, 1996.

MACHADO, N. J. Ensaios Transversais: Cidadania e Educação. São Paulo : Escrituras, 1997.

MARTINEZ, Vinício Carrilho. Educação, Política e Tecnologia na Formação do Cidadão.

Dissertação de Mestrado em Educação. UNESP - Faculdade de Filosofia e Ciências : Marília- SP, 1993-1996. O cidadão de silício. UNESP - Faculdade de Filosofia e Ciências : Marília- SP, 1997. A rede dos cidadãos: a política na Internet. Tese de doutorado em Educação. São Paulo :

Faculdade de Educação da Universidade de São Paulo (FEUSP), 2001.

Estado de (não)Direito: quando há negação da Justiça Social, da Democracia Popular, dos Direitos Humanos. Mestrado em Ciências Jurídicas. Paraná : Universidade Estadual do Paraná - UNESPAR. Faculdade Estadual de Direito do Norte Pioneiro FUNDINOPI, 2005.

O direito à educação no Estado Cientificista - a contribuição dos clássicos das ciências sociais na delimitação da modernidade. Pesquisa de Pós-Doutorado em Ciências Sociais. UNESP/Marília, SP: [s.n.], 2009.

Estado de Exceção e Modernidade Tardia: da dominação racional à legitimidade (anti) democrática. Tese de Doutorado em Ciências Sociais. UNESP/Marília, SP: [s.n.], 2010. Os Códigos da Prudência. Pesquisa de Pós-Doutorado em Ciências Sociais. UNESP/Marília, SP: [s.n.], 2011.

MORA, J. Ferrater. Dicionário de Filosofia. Tomos I, II, III, IV. São Paulo : Loyola, 2001.

SANTOS, Fátima Ferreira P. dos @ MARTINEZ, V. C. Estado penal: a miséria e a venda do Estado de Direito. Perspectivas: Revista de Ciências Sociais (UNESP. Araraquara. Impresso), v. 36, p. 209-235, 2009. 